\title{
Developing tools to link environmental flows science and its practice in Sri Lanka
}

\author{
N. ERIYAGAMA \& K. JINAPALA \\ International Water Management Institute (IWMI), PO Box 2075, Colombo, Sri Lanka \\ n.eriyagama@cciar.org
}

\begin{abstract}
The term "Environmental Flows (EF)" may be defined as "the quantity, timing and quality of water flows required to sustain freshwater and estuarine ecosystems and the human livelihoods and well-being that depend on these ecosystems". It may be regarded as "water for nature" or "environmental demand" similar to crop water requirements, industrial or domestic water demand. The practice of EF is still limited to a few developed countries such as Australia, South Africa and the UK. In many developing countries EF is rarely considered in water resources planning and is often deemed "unimportant." Sri Lanka, being a developing country, is no exception to this general rule. Although the country underwent an extensive irrigation/water resources development phase during the 1960s through to the 1980s, the concept of EF was hardly considered. However, as Sri Lanka's water resources are being exploited more and more for human usage, ecologists, water practitioners and policymakers alike have realized the importance of EF in sustaining not only freshwater and estuarine ecosystems, but also their services to humans. Hence estimation of EF has been made mandatory in environmental impact assessments (EIAs) of all large development projects involving river regulation/water abstraction. Considering EF is especially vital under the rapid urbanization and infrastructure development phase that dawned after the end of the war in the North and the East of the country in 2009. This paper details simple tools (including a software package which is under development) and methods that may be used for coarse scale estimation of EF at/near monitored locations on major rivers of Sri Lanka, along with example applications to two locations on River Mahaweli. It is hoped that these tools will help bridge the gap between EF science and its practice in Sri Lanka and other developing countries.
\end{abstract}

Key words water resources; environmental flows; flow duration curve; natural flow; time series

\section{INTRODUCTION}

The term Environmental Flows (EF) may be defined as "the quantity, timing and quality of water flows required to sustain freshwater and estuarine ecosystems and the human livelihoods and wellbeing that depend on these ecosystems". It may be regarded as "water for nature", "environmental demand" or "environmental water requirements" similar to crop water requirements, industrial or domestic water demand. It is vital that in water resources planning, a certain volume of water is reserved for the maintenance of freshwater ecosystem functions and the services they provide to humans. Ecologists believe that not only the volume of water, but also its variability, are equally important in maintaining the structural and functional diversity of rivers and flood plains (Bunn and Arthington 2002). In arid or dry areas, plants and animals generally adapt to infrequent flow for maintaining health and reproduction. In other areas, when flow regimes of rivers/streams are altered due to dams/water abstractions upstream, sufficient flow at the right times needs to be maintained in the river/stream for the maintenance of aquatic ecosystem services downstream. At times this streamflow requirement may include social and cultural components in addition to the environmental component, e.g. in the case of the holy River Ganga in India (O'Keeffe et al. 2012).

The science and practice of EF is still limited to a few developed countries such as Australia, South Africa and the UK. In many developing countries EF is rarely considered in water resources planning and is often deemed "unimportant." Sri Lanka, as a developing country, is no exception to this general rule. Although the country underwent an extensive irrigation/water resources development phase during the 1960s through to the 1980s, the concept of EF was not/rarely considered. At most, its application was limited to prescription of a minimum flow. For example, in the Mahaweli Development Program (initiated in 1970), which included the construction of five major dams and several diversions along the longest river (River Mahaweli) of Sri Lanka, the allocation of EF below dams was limited to laying down the condition: "the minimum discharge of the Mahaweli should not drop below the historical minimum, in order not to endanger the habitat of fish and other fauna" (NEDECO 1979). 
As Sri Lanka's water resources are being increasingly exploited, the need for sustaining freshwater and estuarine ecosystems and the services that they provide to humans has also gained wider recognition. Hence estimation of $\mathrm{EF}$ has been made mandatory in environmental impact assessments (EIAs) of all large development projects involving river regulation/water abstraction. However, scientifically sound national guidelines and tools for estimation and allocation of EF have not yet been adopted. This paper attempts to fill the above vacuum by introducing simple tools and methods that may be used for coarse scale estimation of EF at/near monitored locations on major rivers of Sri Lanka. An example application of these tools to two locations, one gauged and the other ungauged, on River Mahaweli is also presented. It is hoped that these tools will help ensure healthy ecological functioning of not only the heavily developed rivers like Mahaweli, but also other less developed ones (forming the majority of the total of 103), the resources of which are also under pressure, especially due to the rapid urbanization and infrastructure development activities initiated after the end of the war in the North and the East of the country in 2009.

\section{A DESKTOP ENVIRONMENTAL FLOW CALCULATOR}

A user friendly software package, provisionally called the Sri Lanka Environmental Flow Calculator (SLFC) is currently being developed (Fig. 1(a)). It enables estimation of EF at both gauged and ungauged locations on major rivers of the country, when used in combination with other simple methods for simulation of hydrological data, as illustrated in the examples. Version 1 of the software has already been presented to both regulators and project proponents (water sector agencies in the country) at two stakeholder forums. Both sides have expressed interest in applying and testing the calculator on the ground in order to ascertain its suitability as a major tool for EF estimation in Sri Lanka.

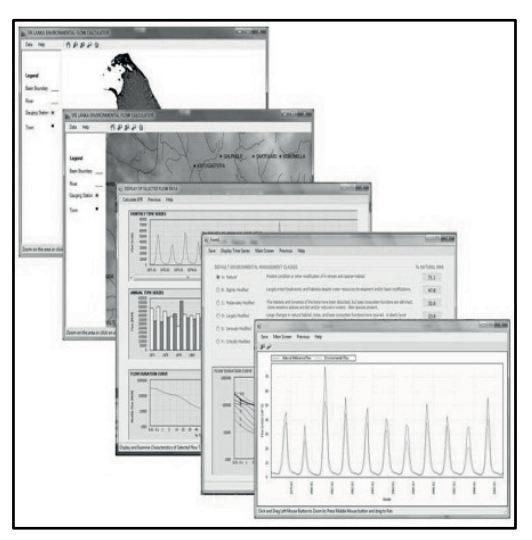

(a)

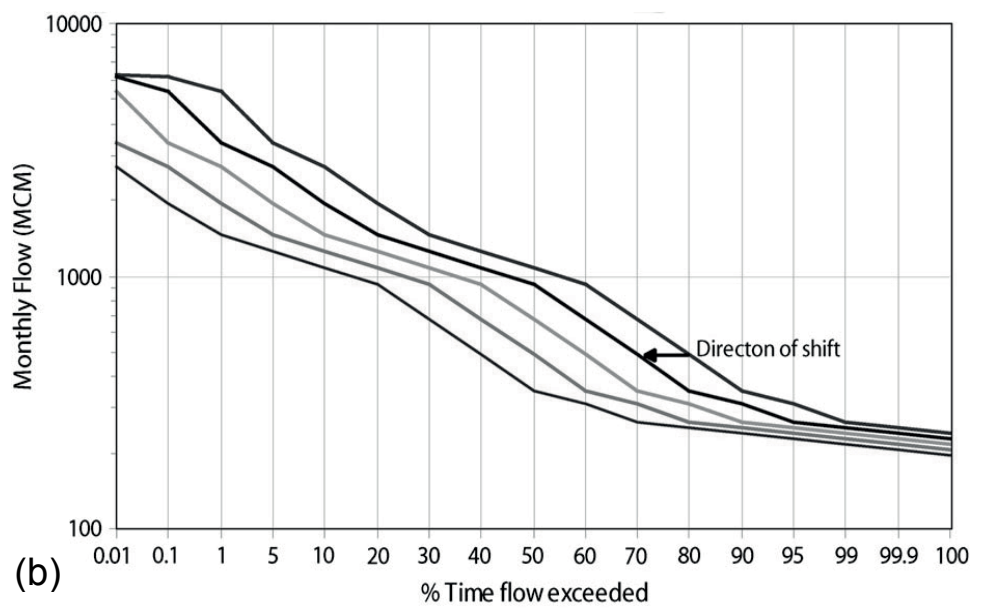

(b)

Fig. 1 (a) Screenshots of the software and (b) natural and environmental FDCs.

The SLFC uses the EF estimation method of Smakhtin and Anputhas (2006). This method converts natural or unregulated monthly flow time series into a period-of-record FDC, a probability distribution function of flows, and subsequently uses this natural or reference FDC to estimate EF (Fig. 1(b)). Natural or unregulated flow is the flow that would occur at a particular location of a river minus any upstream water resources development (dams, diversions or abstractions). The method of Smakhtin and Anputhas (2006) aims to maintain a river ecosystem in, or upgrade it to some prescribed or negotiated condition called an Environmental Management Class (EMC), preserving the natural pattern of the river's flow regime. The higher the EMC, the more water is needed for ecosystem maintenance and more flow variability needs to be preserved. Six EMCs are defined ranging from "unmodified and largely natural" to "seriously and critically modified", named A to F, depending on the condition of the river ecosystem. The reference FDC is represented by a table of flows corresponding to 17 fixed probabilities of exceedence: $0.01 \%, 0.1 \%, 1 \%, 5 \%, 10 \%, 20 \%, 30 \%, 40 \%$, 
$50 \%, 60 \%, 70 \%, 80 \%, 90 \%, 95 \%, 99 \%, 99.9 \%$ and $99.99 \%$. Environmental FDCs corresponding to each EMC are estimated by respective lateral shifts of the original reference FDC to the left along the probability axis by one percentage category (out of the 17) at a time (Fig. 1(b)). The step of a FDC shift of one percentage category has been inferred partially from literature sources (e.g. Tenant 1976, Jones 2002) and partially through limited calibration against EF estimates for Indian rivers (Smakhtin and Anputhas 2006) obtained by the South African Desktop Reserve Model (DRM) of Hughes and Hannart (2003). The estimated environmental FDC is converted back into an environmental flow time series by using an interpolation technique described in Hughes and Smakhtin (1996). This EF assessment method helps to decide: which EMC best describes (if at all) the present flow regime of a river, how far is it from its natural flow regime, and the most feasible EMC for the river to be maintained in given current and future water resources development in the basin.

The use of the tool is demonstrated by applying it to a gauged location (Peradeniya) and an ungauged location (Ullapane) on the upstream reaches of River Mahaweli (Fig. 2). The Kotmale Hydro-electricity Project, located on a tributary of river Mahaweli, slightly upstream of Ullapane (Fig. 2), commenced its operations in June 1985. Construction of the project was initiated in February 1979. The project components include a $87 \mathrm{~m}$ high rock fill dam to store grossly 174 million cubic metres $\left(\mathrm{m}^{3}\right)$ of water, and a tunnel system conveying impounded water to underground turbines, having a combined installed capacity of 201 Mega Watts (MW). After power generation, water is released back to River Mahaweli just upstream of Ullapane.
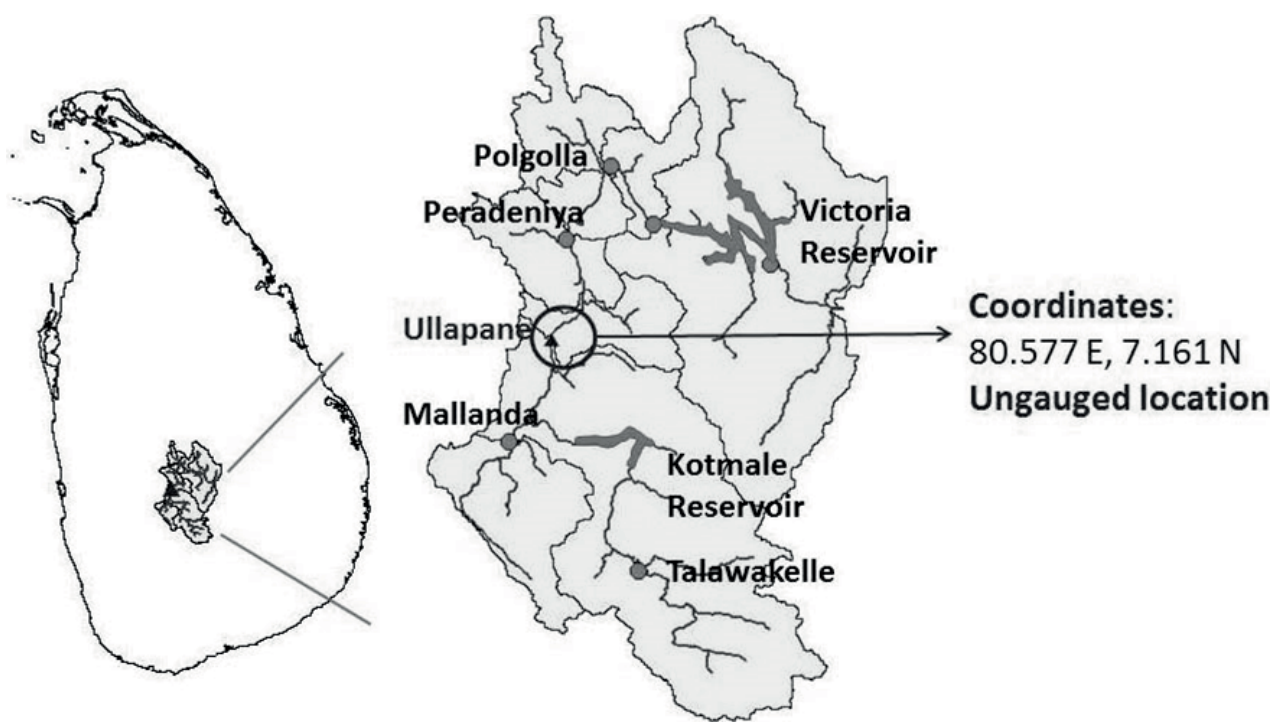

Fig. 2 Location of Peradeniya and Ullapane on River Mahaweli where EF is estimated.

\section{Estimation of EF at gauged locations (Peradeniya)}

The SLFC provides access to a database of historical monthly flow time series at 158 gauged locations on major rivers of Sri Lanka including Peradeniya. The intention here is to provide monthly natural or reference flow time series (the starting point for the estimation of EF) at these 158 locations by naturalizing observed flow records obtained mainly from the Irrigation Department and the Mahaweli Authority of Sri Lanka. While this naturalizing of observed flow records at the 158 locations are in progress, the database currently consists of only observed flow "as is". However, another data option is provided, enabling the user to estimate EF by using his/her own reference flow time series instead of the built in data. The users may naturalize an observed flow time series extracted from the default database or use a separate natural flow data set at the same location that they may have in their possession. One way to naturalize an observed flow record is to identify earlier trends before development and extend them (the method used in applying the tool to Peradeniya). Naturalizing of flows may also be accomplished through either: (a) identifying the quantity and timing of upstream water uses and adding these components to observed flow records, (b) hydrological modelling and 
calibration of current basin conditions, (c) simulating basin flows minus current upstream water withdrawals/abstractions, or (d) using a spatial interpolation technique to generate natural flows using time series data of nearby stations (as demosntrated in applying the tool to Ullapane).

Access to gauged flow time series is provided in the SLFC through selecting points on an interactive geographic map (Fig. 1(a)). Tools are provided for zooming, panning and selecting data points. Progressive zooming exposes a number of data layers including country and river basin boundaries, the river network, major cities, gauged data locations, and a digital elevation model (DEM) of Sri Lanka. The extent of details displayed on the map depends on the current zoom level. By clicking on any particular location where gauged data exists (indicated with markers on the map), the flow time series pertaining to the location of interest may be accessed from the flow database, its main hydrological characteristics displayed, the environmental FDCs for each EMC estimated, and a suitable environmental FDC (EMC) for the river in question selected and converted into an EF time series.

Since the Kotmale Hydro-electricity project is the only known major flow alteration that took place upstream of both Peradeniya and Ullapane in recent times, streamflows that occurred at these locations before commencement of construction work of the Kotmale project are regarded as natural flows. The record length for Peradeniya is from 1942 to 2010. The flow time series from 1942 to 1979 (before alteration) was employed to generate the natural FDC at Peradeniya (Fig. 3(b)). The flow record from 1987 to 2010 was used to generate the altered FDC. This altered FDC was compared with its natural FDC (Fig. 3(b)) and it is seen that the altered flow regime of Peradeniya lies between EMCs A and B.

\section{Estimation of EF at ungauged locations (Ullapane)}

Measured monthly discharge data are also available at Mallanda in this stretch of the river (Fig. 2) for the period before construction of the Kotmale project, and this data is already incorporated in the SLFC. Mallanda is approximately $6 \mathrm{~km}$ upstream of Ullapane while Peradeniya is $17 \mathrm{~km}$ downstream. The SLFC was used to generate the natural FDC at Mallanda (Upstream of Ullapane) too using monthly streamflows before 1979. The natural FDC of Ullapane was generated using those of Peradeniya and Mallanda, assuming that the difference in FDC heights at each percentage category between any two locations in this stretch of the river is proportional to the difference in their respective catchment areas. Hence, for any location X between Mallanda and Peradeniya:

$$
\frac{H_{x}-H_{\text {mallanda }}}{A_{x}-A_{\text {mallanda }}}=\frac{H_{\text {peradeniya }}-H_{\text {mallanda }}}{A_{\text {peradeniya }}-A_{\text {mallanda }}}
$$

where $H_{x}$ represents the FDC height at a particular percentage category (Fig. 3(a)), and $A_{x}$ is the contributing catchment area, at location X. FDC heights $\left(H_{x}\right)$ at all 17 percentage categories for Ullapane was estimated in this manner (Fig. 3(a)) by solving equation (1) for $H_{x}$ with $A_{x}=A_{\text {ullapane }}$. This simulated natural FDC was converted to a monthly time series by using the spatial interpolation technique of Hughes and Smakhtin (1996) considering that flows at any particular month in Peradeniya and Ullapane occur at similar percentage points on their respective FDCs due to their close proximity to each other. Although generation of natural FDCs and flow time series at ungauged locations currently requires the use of a spreadsheet tool, such procedures are envisaged to be built into the SLFC in the future. The simulated natural flow time series at Ullapane was fed into the SLFC to generate environmental FDCs and time series. The altered FDC of Ullapane was generated by extrapolating downwards the altered FDC of Peradeniya by the same ratio in heights between the natural FDCs of the two locations at each of the 17 percentage categories. The altered FDC for Ullapane also lies between those for EMCs A and B.

The two examples above demonstrate how a coarse scale assessment of the current ecological condition of a gauged or ungauged river location (segment) may be made, and possible scenarios of EF may be generated using the SLFC and other simple methods for simulating FDCs and flow time series at ungauged locations. The decision on the most probable (feasible) EMC the river should be 

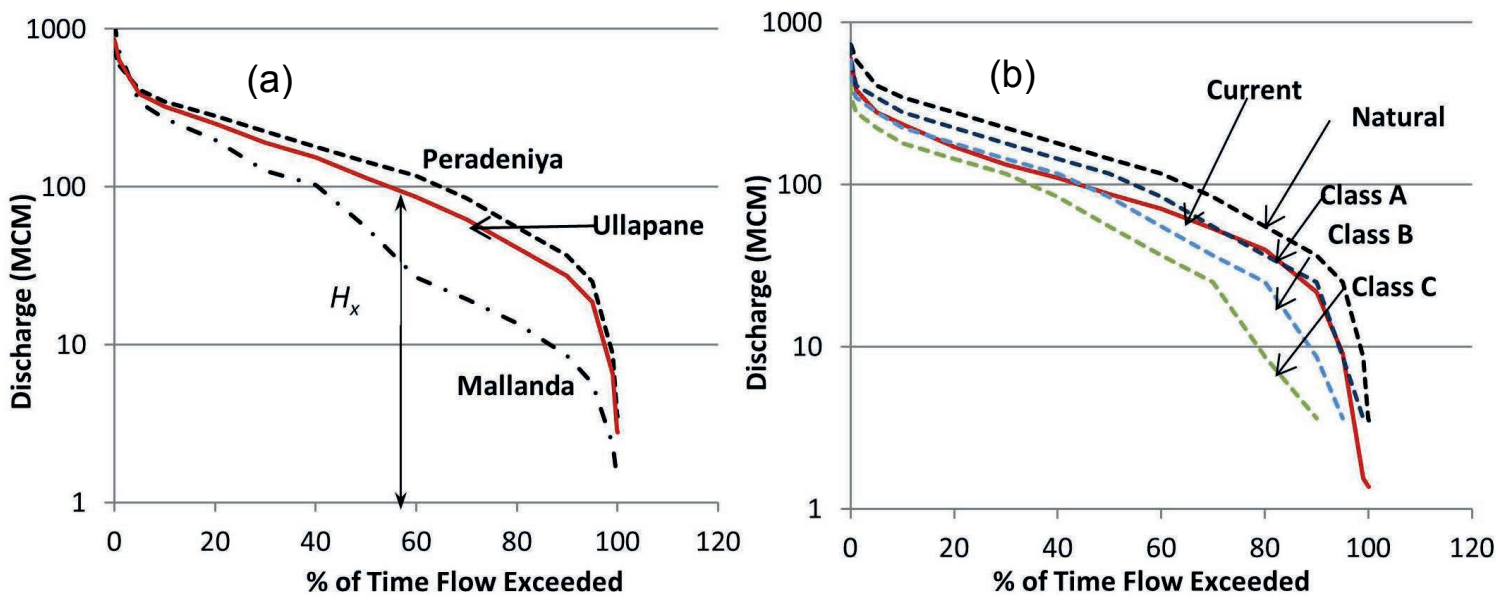

Fig. 3 (a) Simulated Natural FDC of Ullapane (continuous line) and (b) Natural and Environmental FDCs of Peradeniya (dashed lines) compared with the current flow regime (continuous line).

maintained in needs to consider expected water resources development in the future as well as other socio-environmental needs. Once the decision on whether to downgrade, upgrade or maintain the current ecological condition of the river is made, the relevant FDC may be translated into a flow time series (and subsequently into 12 average monthly flows per year) which may be maintained as EF.

\section{CONCLUSIONS}

This paper illustrates the need, and some simple tools and methods for quick coarse scale estimation of EF for major rivers of Sri Lanka. However, it is important to note that these tools provide only a coarse assessment of the ecological status of a river, since its determination is purely based on comparing the river's current FDC with the environmental FDCs. Nevertheless, they do provide a reasonable starting point to decide whether more comprehensive in-depth studies are necessary at the considered location based on its current ecological sensitivity. The main drawback in using the method of Smakhtin and Anputhas (2006) is the limited ecological justification for the shifting procedure to produce environmental FDCs. The shifts need to be calibrated to suit Sri Lankan conditions by establishing the ecological status of rivers where EF is estimated, possibly using an indicator based approach (such as in Smakhtin et al. 2007). Once the current flow regime of a river and its ecological status is established, the two can be correlated to arrive at more realistic shifts to produce environmental FDCs for each class. Another limitation, particularly in using the SLFC, is the low density of currently gauged locations. Of the 103 major rivers in Sri Lanka, no gauged data are available for nearly half of them. One way to overcome data limitations is to increase the data density through hydrological modelling and also construction of virtual gauges with remotelysensed discharge data. A high resolution grid-based streamflow model is an even better alternative to having point data. Recreating the natural flow regime of a river, particularly identifying the time period, which would represent natural conditions, may also prove difficult at certain places. However, even with all its limitations, the SLFC is a tool that can be replicated in other developing countries too to promote the concept of EF and its practice in a simple, easy to use manner if sufficient observed or simulated monthly flow data on major rivers is available. Such a tool will provide planning level guidance on assessing EF where no such guidelines currently exist. With more ecological information added its robustness can be even further improved.

Acknowledgments This research was supported by the CGIAR Research Program on Water Land and Ecosystems (WLE) led by the International Water Management Institute (IWMI). The authors would like to acknowledge the Central Environmental Authority (CEA), all water sector agencies in Sri Lanka including the Department of Irrigation and the Mahaweli Authority, the universities of Colombo and Peradeniya, the IUCN and Practical Action (Sri Lanka) for providing gauged flow 
data and actively participating in project workshops. They would also like to thank Dr Vladimir Smakhtin of IWMI for reviewing this paper.

\section{REFERENCES}

Bunn, S. E. and Arthington, A. H. (2002) Basic principles and ecological consequences of altered flow regimens for aquatic biodiversity. Environmental Management 30, 492-507.

Hughes, D. A. and Hannart, P. (2003) A desktop model used to provide an initial estimate of the ecological in streamflow requirements of South Africa. Journal of Hydrology 270, 167-181.

Hughes, D. A. and Smakhtin, V. U. (1996) Daily flow time series patching or extension: a spatial interpolation approach based on flow duration curves. Journal of Hydrological Sciences 41(6), 851-871.

Jones, G. (2002) Setting environmental flows to sustain a healthy working river. Watershed February 2002. Cooperative Research Centre for Freshwater Ecology, Canberra. http://freshwater.canberra.edu.au

Netherlands Development Company (NEDECO) (1979) Mahaweli Ganga Development Strategy Study; Vol V, Annex K: Environmental Aspects. Colombo, Sri Lanka: NEDECO and Mahaweli Development Board.

O'Keeffe, J., et al. (2012) Assessment of Environmental Flows for the Upper Ganga Basin. WWF-India.

Smakhtin, V. U. and Anputhas, M. (2006) An Assessment of Environmental Flow Requirements of Indian River Basins. IWMI Research Report 107. Colombo, Sri Lanka: International Water Management Institute. 36 pp. http://dx.doi.org/10.3910/2009.106

Smakhtin, V., et al. (2007) Developing Procedures for Assessment of Ecological Status of India River Basins in the Context of Environmental Water Requirements. IWMI Research Report 114. Colombo, Sri Lanka: International Water Management Institute. $34 \mathrm{pp}$.

Tennant, D. L. (1976) Instreamflow flow regimens for fish, wildlife, recreation and related environmental resources. Fisheries 1, 6-10. 